\title{
Genes Involved in Brassinosteroids's Metabolism and Signal Transduction Pathways
}

\author{
Adaucto Bellarmino Pereira-Netto* \\ Departamento de Botanica; Setor de Ciências Biológicas; Universidade Federal do Paraná; Centro Politecnico; \\ C.P. 19031; 81531-970; apereira@ufpr.br; Curitiba-PR - Brasil
}

\begin{abstract}
Brassinosteroids (BRs) are plant steroids essential for the normal growth and development, which carry an oxygen moiety at C-3 and additional ones at one or more of the C-2,C-6,C-22 and C-23 carbon atoms. In the past few years, application of molecular genetics allowed significant progress on the understanding of the BRs biosynthetic pathway regulation and on the identification of several components of their signal transduction pathway, as well. Search in eletronic databases show dozens of records for brassinosteroid-related genes for the last twelve months, demonstrating the big efforts being carried out in this field. This review highlights the recent advances on the characterization of genes and mutations that are helping to unravel the molecular mechanisms involved in the BRs synthesis/metabolism, perception and response, with especial emphasis on their role in plant cell elongation. Aspects of the involvement of BRs on the regulation of cell cycle-controlling proteins are discussed as well.
\end{abstract}

Key words: Brassinolide, cell elongation, dwarf, signal perception

\section{INTRODUCTION}

The most recently discovered class of the plant growth regulators, the brassinosteroids (BRs), is a family of about 60 phytosteroids (Bajguz and Tretyn, 2003). Application of molecular genetics in the past few years has led to rapid progress toward understanding these steroids's biosynthetic pathway regulation and the identification of several components of their signal transduction pathway as well. Indeed, BRs signaling is now considered to be one of the best-understood signal transduction pathways in plants (Russinova et al., 2004).

The genetic approach used to identify the components of the BR biosynthetic and signal transduction pathways have relied on the isolation and characterization of mutants deficient in BRs biosynthesis or response. The availability of these mutants has played a major role in the increase in the knowledge concerning BRs (Clouse and Sasse, 1998; Li and Chory, 1999; Bishop and Yokota, 2001; Clouse, 2002). BR-deficient mutants usually result from lesions in genes encoding for BR biosynthetic enzymes and are rescued to the wild type phenotype by exogenously supplied BRs (Szekeres et al., 1996; Choe et al., 1998, 2000). Whereas, BR-insensitive mutants usually result from lesions in genes encoding for the receptor or other elements in the BRs signal transduction pathway, and although these mutants may present the same phenotype as BRs-deficient mutants, they are not rescued by exogenously supplied BRs (Clouse et al., 1996; Li et al., 2001b; Yin et al.,

* Author for correspondence 
2002). Some characteristics are typical for both, BR-deficient and BR-insensitive mutants. In Arabidopsis thaliana, for example, all BR mutants show male sterelity or reduced female fertility, drastic dwarfism and reduced apical dominance. When grown in darkness, these mutants present reduced hypocotyl elongation, unregulated opening of cotyledons, and emergence of primary leaves (Creelman and Mullet, 1997). The BRdeficient and BR-insensitive mutants and their correspondent cloned genes are powerful tools intensively used to investigate not only the physiological functions but also the biosynthetic and signal transduction pathways of BRs.

Microarray analysis of BR-regulated genes in Arabidopsis showed that 59 up-regulated genes and 36 down-regulated genes were reproducibly regulated by brassinolide (BL) (Goda et al., 2002), the most active BR. From this list, P450 genes and transcription factor genes predominated among down-regulated genes, while auxin-related genes and genes that were implicated in cell elongation or cell wall organization predominated among upregulated genes. Yang and colleagues (2003), using microarray analysis in plants of rice, identified 12 genes with strongly enhanced expression after BL treatment, 14 genes with weakly enhanced expression after BL treatment and 12 genes with repressed expression, indicating that the broader use of this technique would very likely significantly increase the knowledge about BR-regulated genes in a wide variety of plant species in a near future.

This review highlights the advances on the characterization of genes and mutations that are helping to unravel the molecular mechanisms involved in the BRs synthesis/metabolism, perception and response, with especial emphasis on their role in plant cell elongation. Aspects of the involvement of BRs on the regulation of activity of D-type cyclins, proteins thought to be critical for the stimulation of cell division, and also to play key roles in linking the plant cell cycle to extracellular and developmental signals, are discussed as well. Having insight the large number and complexity of cross-talk networks between BRs and other plant growth regulators, along with the limited length for the reviews, these interactions will not be discussed in this review.

\section{Genes Involved in the Biosynthesis of BRs}

The BR biosynthetic pathways consist of two major parts, sterol biosynthesis and a BR-specific pathway. Analysis of BR metabolic gene expressions indicate that $\mathrm{BR}$ homeostasis is maintained through feedback expressions of multiple genes, each of which is involved not only in BR-specific biosynthesis and inactivation, but also in sterol biosynthesis (Tanaka et al., 2005).

\section{The $d w f$ (dwarf) group}

Nine BR dwarf loci in Arabidopsis, $d w f 1$ to $d w f 8$, and $d w f 12$, have been reported. The $d w f 1, d w f 5$, and $d w f 7$ mutants are defective in sterol biosynthesis, and a second group including $d w f 3$, $d w f 4, d w f 6$, and $d w f 8$ belong to the BR specific pathway. Only $d w f 2$ and $d w f 12$ mutants are insensitive to bioactive BRs. $d w f 1, d w f 2, d w f 3$, and $d w f 6$ were found to be allelic to diminutol $(\operatorname{dim} 1)$, cabbagel ( $c b b 1$ ) from Arabidopsis and possibly $l k b$ (from pea); bril, cbb2 and 18 bin (from Arabidopsis); Arabidopsis cpd, tomato dpy and Arabidopsis cbb3; and Arabidopsis det2, respectively (see Table 1). As expected, except for $d w f 2$ and $d w f 12$ alleles, all of the dwf mutants are highly responsive to exogenously supplied BRs.

$\boldsymbol{d} \boldsymbol{w f 1}$. The $d w f 1$ was the first BR-related gene identified to be cloned (B.P. Dilkes and K.A. Feldmann, personal communication) (Choe et al., 1998). The three alleles dwarfl (dwfl), dim (Takahashi et al., 1995; Klahre et al., 1998) and cbbl (Kauschmann et al., 1996), were defective in the synthesis of campesterol from 24methylenecholesterol and $l \mathrm{~kb}$ is the equivalent mutant in pea (Pisum sativum) (Nomura et al., 1997; 1999). Analysis of the endogenous levels of BR intermediates showed that 24methylenecholesterol in $d w f 1$ accumulated to 12 times the level found for the wild type (Choe et al., 1999a). In the $l k b$ mutant the levels of BL, castastherone (CS), another very active BR, and 6deoxoCS, campestanol, and campesterol were severely reduced in young shoots, however, levels of 24-methylenecholesterol were elevated, compared to those of wild-type plants (Nomura et al., 1997, 1999). Furthermore, the deduced amino acid sequence of $d w f l$ showed significant similarity to a flavin adenine dinucleotide-binding domain conserved in various oxidoreductases, suggesting an enzymatic role for $d w f l$ (Choe et al., 1999a). 
dwf 3. $d w f 3$ mutants have only been rescued by 23-alpha-hydroxylated BRs. These mutants have also been found to be allelic to cpd (Choe et al., 1998), a mutant described below.

$\boldsymbol{d w f 4}$. The $d w f 4$ mutant was also shown to be defective in the BR biosynthetic pathway, more specifically in a steroid $22 \alpha$-hydroxylation (CYP90B1), presenting 513 aminoacids and 43\% identity and $66 \%$ similarity with the $c p d$ gene (Choe et al., 1998), described below, which catalized a key regulatory step in BRs biosynthesis (Choe et al., 2001). Choe and co-workers (2001) have shown that transgenic Arabidopsis plants overexpressing $d w f 4$ (aod4) presented dramatical increase in hypocotyl length in both light- and dark-grown as compared to wild type. Analysis of endogenous levels of BRs in $d w f 4$ and aod4 revealed that $d w f 4$ accumulated the precursors of the $22 \alpha$-hydroxylation steps, while overexpression of $d w f 4$ resulted in enhanced levels of downstream compounds relative to controls.

$d w f 5, d w f 6, d w f 7, d w f 8, d w f 11$ and $d w f 13 . d w a r f 5$ (dwf5) has been shown to be defective in the reduction of 5-dehydroepisterol to 24methylenecholesterol (Bishop and Yokota, 2001). In addition to that metabolite tracing with C-13labeled precursors in $d w f 5$ demonstrated that the mutant phenotype was caused by loss-of-function mutation in a sterol $\Delta^{7}$ reductase gene (Choe et al., 2000). dwarf6 (dwfo) and its allele deetiolated 2 (det2), described below, were mutants in a $5-\alpha-$ steroid reductase ( $\mathrm{Li}$ et al., 1996; $\mathrm{Li}$ et al., 1997) that linked campesterol to campestanol by catalyzing the conversion of (24R)-24methylcholest-4-en-3-one to (24R)-24-methyl-5 $\propto$ cholestan-3-one (Fujioka et al., 1997; Noguchi et al., 1999; Bishop and Yokota, 2001).

Feeding studies with intermediates of the BR biosynthetic pathway and analysis of endogenous BRs and intermediates of the sterol biosynthetic pathway have shown that the defective step in $d w f 7$ resided before the production of 24methylenecholesterol in the sterol biosynthetic pathway, more specifically the dehydrogenation of episterol to 5-dehydroepisterol, indicating that $d w f 7$ was an allele of the previously cloned Arabidopsis steroll (stel) gene (Choe et al., 1999b; Bishop and Yokota, 2001). Similar studies in the dwf8 mutant indicated that the biosynthetic defect in this mutant was located in the most downstream step yet to be genetically identified (Choe et al., 1998, personal communication).

dwarf11, a rice (Oryza sativa) dwarf mutant, was defective for a novel cytochrome P450 (CYP724B1), which showed homology to enzymes involved in BR biosynthesis. The dwarf 11 gen is feedback-regulated by BL. Several lines of evidence suggest that the dwarf11/cyp $724 b 1$ gene plays a role in BR synthesis and may be involved in the supply of 6-deoxotyphasterol and typhasterol in the BR biosynthesis network in rice (Tanabe et al., 2005).

An Arabidopsis BR-insensitive mutant, named $d w f 12$ was recently reported (Choe et al., 2002) as follows. The dwarf (d) mutant of tomato represented a new locus encoding a P450 that was classified as CYP85 (Bishop et al., 1999). The CYP85A family members (e.g. CYP85A1; CYP85A3, CYP85A2) catalyze the formation of CS from 6-deoxoCS (Nomura et al., 2005) via the hydroxylated form of 6-deoxoCS which is the key step linking the late C- 6 oxidation pathway to the early C-6 oxidation pathway (Bishop et al., 1999). The CYP85A family members have high homology to CPD and DWF4 (Bishop et al., 1999).

cpd. Rescue of the Arabidopsis cpd (constitutive photomorphogenesis and dwarfism) mutant showed that CPD/CYP90A1, a member of the CYP90 family, functions as C-23 steroid hydroxylase (Szekeres et al., 1996). Rescue of the dwarf phenotypes of cpd mutants by BR intermediates indicates that CYP90A1 and CYP90B1 are responsible for the C-23 and C-22 side chain hydroxylation reactions in both the early and late C-6 oxidation pathways of BR biosynthesis (Choe et al., 1998; Li and Chory, 1997). The Rotundifolia3 (rot3) gene, encoding the enzyme CYP90C1, has been recently shown to be required for the late steps in the BR biosynthesis pathway. rot3 seems to be required for the conversion of typhasterol to CS, an activation step in the BR pathway (Kim et al., 2005).

cpy. The dumpy (dpy) mutant of tomato (Lycopersicon esculentum Mill.) exhibited short stature, reduced axillary branching, and altered leaf morphology (Koka et al., 2000). Application of BL and CS to dpy plants resulted in a nearly complete rescue of the mutant phenotype, while the late C- 6 oxidation pathway intermediates 6- 
deoxoteasterone, 6-deoxo-3-dehydroteasterone, 6deoxotyphasterol, and 6-deoxoCS also presented significant effect on dpy leaf development, although the overall plant height and branching were not as pronounced as with CS and BL (Koka et al., 2000). However, intermediates upstream of 6-deoxoteasterone, including campesterol, campestanol, and 6-deoxocathasterone, had no noticeble effect on leaf phenotype or height. The considerable difference in leaf morphology between 6-deoxoteasterone-treated dpy plants and later pathway intermediates, compared with 6deoxocathasterone-treated plants and earlier pathway intermediates-treated plants, suggested that conversion of 6-deoxocathasterone to 6deoxoteasterone might be blocked in the dpy mutant. Measurement of the endogenous BR levels showed that both dpy and wild-type plants presented similar levels of the BR precursors 24methylenecholesterol, campesterol, and campestanol. However, dpy plants had two times the level of 6-deoxocathasterone compared to the wild type and less than $50 \%$ the amount of 6deoxoteasterone. Koka and collegues (2000) found that dpy plants had a 25 -fold reduction in 6deoxoCS levels, and CS was below the detection limit in the mutant. Those results showed clearly that dpy was in fact BR deficient and the biochemical data were consistent with the feeding experiments, which suggested that dpy mutants had reduced ability to convert 6-deoxocathasterone into 6-deoxoteasterone (Koka et al., 2000). Finally, since the cpd gene of Arabidopsis likely encode a C-23 steroid hydroxylase responsible for the conversion of cathasterone to teasterone (Szekeres et al., 1996), and also possibly hydroxylate 6-deoxocathasterone to 6deoxoteasterone, $d p y$ was the putative tomato homolog of $c p d$ (Koka et al., 2000).

det2 ("deetiolated"2). The Arabidopsis det2 gene (Chory et al., 1989) was shown to encode a protein that shares significant sequence identity with steroid $5 \alpha$-reductases of mammals, enzymes involved with steroids metabolism in animals $(\mathrm{Li}$ et al., 1996). Mutants det 2 presented only $8-15 \%$ of the campestanol levels found in the wild type and less than $10 \%$ of the wild type levels of other BRs. Mutants det 2 were also unable to convert $\mathrm{H}^{2}$ campesterol into $\mathrm{H}^{2}$-campestanol, demonstrating that det2 mutantes were deficient in brassinoesteroids (reviewed in $\mathrm{Li}$ and Chory, 1999). Additional support to this finding came from rescue experiments in which all intermediates of the BRs biosynthetic pathway after the reaction catalyzed by det 2 were able to rescue det 2 mutant phenotypes ( $\mathrm{Li}$ et al., 1996; Li and Chory, 1999). The analysis of the endogenous BR contents indicated that the $l k$ mutant might be the equivalent of Arabidopsis det 2 in pea. Indeed, the pea gene homologous to the det 2 gene, Psdet 2 , had been cloned, and the $l k$ mutation was found to result in a putative truncated PsDET2 protein. Thus, it was concluded that the $l k$ mutation was due to a defect in the steroidal $5 \alpha$-reductase [3oxo-5- $\alpha$-steroid 4-dehydrogenase] gene (Nomura et al., 2004).

bas1-d. The mechanisms connecting light and hormone signaling are still not well understood. Neff and co-workers (1999) identified a new Arabidopsis mutant, bas1-D (phy $B$ activationtagged suppressor1-dominant), caused by the enhanced expression of the cytochrome P450 monooxigenase: CYP734A1, formerly CYP72B1. The Arabidopsis bas1-D mutation suppressed the long hypocotyl phenotype caused by mutations in the photoreceptor phytochrome B (phyB). Seedlings with reduced basl expression are hyperresponsive to $\mathrm{BRs}$ in a light-dependent manner and display reduced sensitivity to light under a variety of conditions. Biochemical evidences suggest that bas 1 and sob7 (Suppressor of Phyb-4 7) gene, a homolog of basl, act redundantly reducing the level of active BRs through unique mechanisms. Overexpression of sob7 results in a dramatic reduction in endogenous CS levels, and although single null-mutants of basl and sob7 have the same level of CS as the wild type, the double null-mutant has twice the amount. Application of BL to overexpression lines of bas 1 or $s o b 7$ results in enhanced metabolism of BL, although only basl overexpression lines confer enhanced conversion to 26-OHBL, suggesting that $s o b 7$ and bas 1 convert $\mathrm{BL}$ and CS into unique products (Turk et al., 2005).

An Arabidopsis mutant, shrinkl-d (shkl-d), has been shown to be caused by activation of the cyp 72 cl gene, a member of the cytochrome P450 monooxygenase gene family similar to bas1/cyp734al that regulates BR inactivation. However, unlike bas1/cyp $734 a 1$ the expression of cyp $72 c 1$ is not changed by application of exogenous BL (Takahashi et al., 2005). 
Table 1 - Summary of the available/proposed informations for genes involved in the biosynthesis or signal transduction pathway of brassinosteroids

\begin{tabular}{|c|c|c|c|c|}
\hline Gene & Encoded protein & $\begin{array}{l}\text { Metabolic step } \\
\text { affected/physiological defect }\end{array}$ & $\begin{array}{l}\text { Allele/ } \\
\text { Equivalents }\end{array}$ & References \\
\hline$d w f 1$ & Oxido-reductase & $\begin{array}{l}\text { 24-methylenecholesterol } \rightarrow \text { 24- } \\
\text { methyldesmosterol } \\
\text { 24-methylenecholesterol } \rightarrow \\
\text { campesterol }\end{array}$ & $\begin{array}{l}\operatorname{dim} 1, c b b 1, \\
l k b\end{array}$ & $\begin{array}{l}\text { Feldmann et al., 1989; Takahashi et } \\
\text { al., } 1995 \\
\text { Klahre et al., 1998; Nomura et al., } \\
1999 \\
\text { Kauschmann et al., 1996; Choe et } \\
\text { al., 1999a. }\end{array}$ \\
\hline$d w f 2$ & Receptor-kinase & Insensitivity & $\begin{array}{l}\text { bri1, cbb2, bin (n) } \\
l k a, c u 3, a b s 1\end{array}$ & $\begin{array}{l}\text { Clouse et al., 1996; Li \& Chory, } \\
\text { 1997, 1999b } \\
\text { Bishop \& Yokota, 2001; Montoya } \\
\text { et al., } 2002\end{array}$ \\
\hline$d w f 3$ & $23 \alpha$ - hydroxylase (CYP90A1) & $\begin{array}{l}\text { 6-deoxocathasterone } \rightarrow 6 \text { - } \\
\text { deoxoteasterone } \\
\text { cathasterone } \rightarrow \text { teasterone }\end{array}$ & $\begin{array}{l}c p d, c b b 3 \\
d p y\end{array}$ & $\begin{array}{l}\text { Szekeres et al., 1996Choe et al., } \\
1998 \\
\text { Clouse \& Sasse, } 1998\end{array}$ \\
\hline$d w f 4$ & $22 \alpha$ - hydroxylase (CYP90B1) & $\begin{array}{l}\text { Campestanol } \rightarrow 6 \text { - } \\
\text { deoxocathasterone } \\
\text { 6-oxocampestanol } \rightarrow \\
\text { cathasterone }\end{array}$ & & $\begin{array}{l}\text { Azpiroz et al., } 1998 \\
\text { Choe et al., } 1998\end{array}$ \\
\hline$d w f 5$ & $\Delta^{7}$ sterol reductase & $\begin{array}{l}\text { Mevalonic acid } \rightarrow 24- \\
\text { methylenecholesterol }\end{array}$ & & Choe et al., 2000 \\
\hline$d w f 6$ & $5 \alpha$-steroid reductase & $\begin{array}{l}\text { (24R)-24-methylcholest-4-ene- } \\
\text { 3-one } \rightarrow \\
\text { (24R)-24-methyl-5 } \alpha \text { - } \\
\text { cholestane-3-one }\end{array}$ & $\operatorname{det} 2, l k(?)$ & Choe et al., 1998 \\
\hline$d w f 8$ & $?$ & Sterol biosynthetic pathway & & $\begin{array}{l}\text { Choe et al., 1998, personal } \\
\text { communication }\end{array}$ \\
\hline$d w f 7$ & $\Delta^{7}$ sterol C-5 desaturase & $\begin{array}{l}\text { Mevalonic acid } \rightarrow 24- \\
\text { methylenecholesterol }\end{array}$ & sterol 1 & Choe et al., $1999 \mathrm{~b}$ \\
\hline$d w f 8$ & Unknown & & & Reviwed in Li \& Chory, 1999 \\
\hline$d w f 11$ & $\begin{array}{l}\text { Cytochrome P-450 } \\
\text { (CYP724b1) }\end{array}$ & BR biosynthesis & & Tanabe et al., 2005 \\
\hline$d w f 12$ & Glycogen synthase kinase & Insensitivity & & Choe et al., 2002 \\
\hline$d w f(d)$ & Cytochrome P-450 (CYP85) & 6-deoxoCS $\rightarrow \mathrm{CS}$ & & Bishop et al., 1999 \\
\hline bas & C-26 hydroxylase (CYP734A1) & $\begin{array}{l}\text { Brassinolide } \rightarrow 26-\mathrm{OH} \\
\text { brassinolide }\end{array}$ & & $\begin{array}{l}\text { Neff et al., 1999; Takahashi et al., } \\
\text { 2005; Turk et al., } 2005\end{array}$ \\
\hline brdl & BR-6-oxidase & Multiple C- 6 oxidations & & Mori et al., 2002 \\
\hline $\operatorname{sax}$ & $?$ & $\begin{array}{l}3 \beta, 22 \text {-dihydroxyl- } \Delta^{5,6} \rightarrow 3 \text {-oxo- } \\
\text { 22-hydroxy- } \Delta^{4,5}\end{array}$ & & Ephritikhine et al., 1999 \\
\hline $\begin{array}{l}\text { bakl- } \\
1 D\end{array}$ & Protein kinase & Insensitivity & & Li et al., 2002 \\
\hline bim1 & (bHLH) proteins & Transcription factor & & Yin et al., 2005 \\
\hline $\begin{array}{l}\text { bee } 1,2, \\
3\end{array}$ & (bHLH) proteins & Transcription factors & & Friedrichsen et al., 2002 \\
\hline bes 1 & $\begin{array}{l}\text { Nuclear protein } \\
\text { (bri1 supression) }\end{array}$ & Insensitivity & & Yin et al., 2002 \\
\hline $\operatorname{bin} 2$ & Glycogen synthase quinase & Insensitivity & & Li et al., 2001a \\
\hline brs 1 & Carboxypeptidase & $\begin{array}{l}\text { Modulation of signal } \\
\text { transduction }\end{array}$ & & Li et al., $2001 b$ \\
\hline brul & XET & Inibition of signal transduction & & Oh et al., 1998 \\
\hline bsul & Nuclear phosphatase & $\begin{array}{l}\text { Modulation of signal } \\
\text { transduction }\end{array}$ & & Mora-Garcia et al., 2004 \\
\hline bzrl & Nuclear protein & Insensitivity & & Wang et al., 2002 \\
\hline $\operatorname{tch} 4$ & XET & Inibition of signal transduction & & Xu et al., 1995 \\
\hline
\end{tabular}


sax. Phenotypic rescue experiments of the saxl mutation of Arabidopsis using synthetic BRs suggest that saxl is involved in the conversion of $3 \beta, 22$-dihydroxyl- $\Delta^{5,6}$ precursors to 3-oxo-22hydroxy- $\Delta^{4,5}$ steroids, the first step of the hypotetical C22 $\alpha$-hydroxy pathway. Furthermore, recovery of wild-type phenotypes of root elongation in the light and of hypocotyl elongation in the dark suggests that saxl is mutated in a step of the pathway that is active in light and dark as well (Ephritikhine et al., 1999).

brd1. $\operatorname{brdl}(\mathrm{BR}-\mathrm{dependent} 1$ ), a recessive rice (Oryza sativa L. Cv. Nipponbare) mutant showing reduction in cell length also displays constitutive photomorphogenesis under darkness (Mori et al., 2002). Exogenously supplied BL has been shown to considerably restore the normal phenotypes. In addition to that, the analyses of endogenous sterols and BRs indicated that BR-6-oxidase, a BR biosynthesis enzyme, would be defective, and, indeed, a $0.2-\mathrm{kb}$ deletion was found in the genomic region of osbr6ox (a rice BR-6-oxidase gene) in the $b r d l$ mutant, indicating that the defect of BR-6-oxidase caused the $b r d 1$ phenotype.

bls1. Recently, an Arabidopsis mutant impaired in light- and BR induced responses as well as in sugar signaling has been described (Laxmi et al., 2004). For its photomorphogenic responses, bls 1 (BR, light and sugar1) resembles BR biosynthetic mutants cpd and det2, however, bls 1 is not allelic to either of these mutants. In addition to that, the mutant retains a normal perception/sensing mechanism for BRs.

\section{Genes Involved in the Signal Transduction Pathway of BRs}

bri1. From Arabidopsis, Clouse and colleagues (1996) identified the first BL insensitive mutant, BL insensitive1 (bril) (Figure 1). BRI1 has been cloned and shown to encode a receptor kinase with an extracellular domain (Li and Chory, 1997), which appear to contain 24 rather than 25 leucinerich repeats (LRRs), with LRR21 (formerly LRR22) being an unusual methionine-rich repeat (Vert et al., 2005). The intracellular region could be subdivided into a juxtamembrane, followed by a canonical serine/threonine kinase and a short Cterminal extension (Vert et al., 2005). It has been recently demonstrated that brassinolide binds directly to both, native and recombinant BRI1 proteins (Kinoshita et al., 2005). Friedrichsen and colleagues (2000) demonstrated that a BRI1::GFP (GFP, green fluorescent protein) fusion protein was located at the plasma membrane, which, along with the protein acting Ser/Thr phosphorylation suggested that BRs were perceived at the cell surface. A dramatic increase of BL binding activity in the membrane fractions of the BRI1::GFP transgenic plants was also found, which was due to an increase of binding sites with similar binding afinities (Wang et al., 2001).

Since all of the over 20 BR-insensitive mutants reported to date, such as $c b b 2,18$ bin and 3 alleles of $d w f 2$, were all allelic to bril (Clouse and Sasse 1998; Li and Chory, 1999), one might conclude that: 1. BRI1 was the only unique and specific component of the BRs signal transduction pathway; 2 . The other components of the pathway are either redundant or shared with other signalling cascade (Li and Chory, 1999; Li et al., 2001b); 3. Mutations in other genes involved in BR signal transduction are lethal (Koka et al., 2000). Recently, Nam and Li (2004) identified an A. thaliana transthyretin-like protein (TTL) as a potential bril substrate. TTL interacts with BRI1 in a kinase-dependent way in yeast and is phosphorylated by BRI1 in vitro. In addition, TTL presents a similar expression pattern with BRI1 and is associated with the plasma membrane.

The curl-3 (cu-3) mutant (Lycopersicon pimpinellifolium [Jusl.] Mill.) shows severe dwarfism, modified leaf morphology, deetiolation, and reduced fertility, and all of these features are strikingly similar to the bril mutant of Arabidopsis. Elongation in primary roots of wildtype L. pimpinellifolium seedlings was strongly inhibited by BR application, while $c u-3$ mutant roots were capable to elongate at the same BR concentration (Koka et al., 2000). The tomato partially BR-insensitive mutant altered brassinolide sensitivityl (absl) was a weak allele of cu3 (Montoya et al., 2002). Using sequence analysis of tBRI1 in the mutants $c u 3$ and $a b s 1$, Montoya and co-workers (2002) demonstrated that cu3 was a nonsense mutant and that absl is a missense mutant. The $l k a$ pea dwarf has increased levels of endogenous BRs and is insensitive to BL treatment (Nomura et al., 1997). Indeed, the $l k a$ mutant has been shown to be defective in the BR receptor kinase PsBRI1 (Nomura et al., 2003). 
bak1-1d. Li and co-workers (2002) identified in Arabidopsis a dominant genetic suppressor of bril, bakl-1d (bri1-associated receptor kinase 11Dominant). This gene encodes an LRR-RLK serine/threonine protein kinase, which interact with bril. bril and bakl can phosphorylate each other, being the autophosphorylation activity of bakl enhanced by bril. Expression of a bakldominant-negative mutant allele results in severe dwarf phenotype, mimicking the phenotype of null bril alleles. The BRI1-BAK1 receptor complex is now thought to initiates BR signaling (Russinova et al., 2004). Studies using atserk3 (Arabidopsis Somatic Embryogenesis Receptorlike Kinase3) a gene identical to bak $1-1 d$, showed that bril, but not atserk3, homodimerizes in the plasma membrane, while bril and atserk3 preferentially heterodimerize in the endosomes (Russinova et al., 2004). Today, bakl is believed to act as a coreceptor and/or downstream target of bril (Vert et al., 2005).

bzrl and bes1. A dominant mutation in Arabidopsis, bzrl-1d, suppresses BR-deficient and BR-insensitive (bril) phenotypes (Wang et al., 2002). BZR1 is a transcriptional repressor that binds directly to the promoters of feedbackregulated BR biosynthetic genes (He et al., 2005). The BZR1 protein accumulates in the nucleus of elongating cells of dark-grown hypocotyls and has been shown to be a positive regulator of the BR signaling pathway (Wang et al., 2002). Thus, BZR1 coordinates BR homeostasis and signaling by playing dual roles in regulating $B R$ biosynthesis and downstream BR responses.

Yin and co-workers (2002) have identified in Arabidopsis besl, a novel plant-specific transcription factor (Li and Deng, 2005). besl is a semidominant suppressor of bril which exhibits constitutive BR response phenotypes such as constitutive expression of BR-response genes. besl, which accumulates in the nucleus in response to BRs, is phosphorylated and apparently is destabilized by the glycogen synthase kinase-3 (GSK-3) bin2, a negative regulator of the BR pathway (see more details below).

BZR1-BES1 family of proteins directly binds to and regulates BR-responsive genes, which establish a link between hormonal signal transmission in the cytoplasm and transcriptional status change in the nucleus (Li and Deng, 2005).
Through the use of a yeast two-hybrid approach using BES1 as a bait, Yin and co-workers (2005) identified the bHLH transcription factor BIM1 in Arabidopsis. BIM1 and BES1 have been shown to be able to bind CANNTG E-box motifs in the promoter of a saur-acl BR responsive gene and likely to form a heterodimer. Many bHLH transcription factors are known to bind to those Ebox motifs (reviewed in Vert et al., 2005).

brs1. Li and collegues (2001b) identified in Arabidopsis brs1-1d, for bri1 suppressorDominant, which encoded a secreted serine carboxypeptidase (Zhou and Li, 2005). brsl-1d suppressed multiple bril-5 defects. This suppression was selective for bril, and dependent on BR, and a functional BRI1 protein kinase domain. In addition, overexpressed brs 1 missense mutants, predicted to abolish BRS1 protease activity, failed to suppress bril-5.

bin2-1 and bin2-2. BR insensitive 2 (bin2-1 and bin2-2) mutants, isolated from Arabidopsis (Li et al., 2001b) exhibit insensitivity to BL, but hypersensitivity to ABA. bin2 has been found to encode an Arabidopsis ortholog of human glycogen synthase kinase $\beta$ and Drosophila SHAGGY protein kinase (Li and Nam, 2002). Interestingly, a mutation in the same kinase gene has also been found to be carried by the ultracurvata1 (ucul) Arabidopsis mutant (PerezPerez et al., 2002). Phenotype and map position of bin2 mutations indicate that these mutants are likely to be alleles of the ucul gene (Berná et al., 1999). Overexpression of bin2 in a weak bri1 mutant background generated a more-pronounced dwarf phenotype. In contrast, co-suppression studies of $\operatorname{bin} 2$ transcription indicate that reduced bin2 levels have only a weak effect on plant growth. When seen together, these data indicate that $\operatorname{bin} 2$ is a negative regulator of BL signaling. It has also been thought that BRI1 may interact with and phosphorylate BIN2 to inactivate it ( $\mathrm{Li}$ and Nam, 2002), but BIN2 do not present close homology to the consensus sequence surrounding the preferred serines that BRI1 is likely to phosphorylate (Oh et al., 2000), consequently, BRI1 is thus not likely to interact directly with the BIN2 kinase. Li and Nam (2002) have also suggested that BIN2 is constitutively active in the absence of BRs and phosphorylates positive BR signaling proteins to inactivate them. 


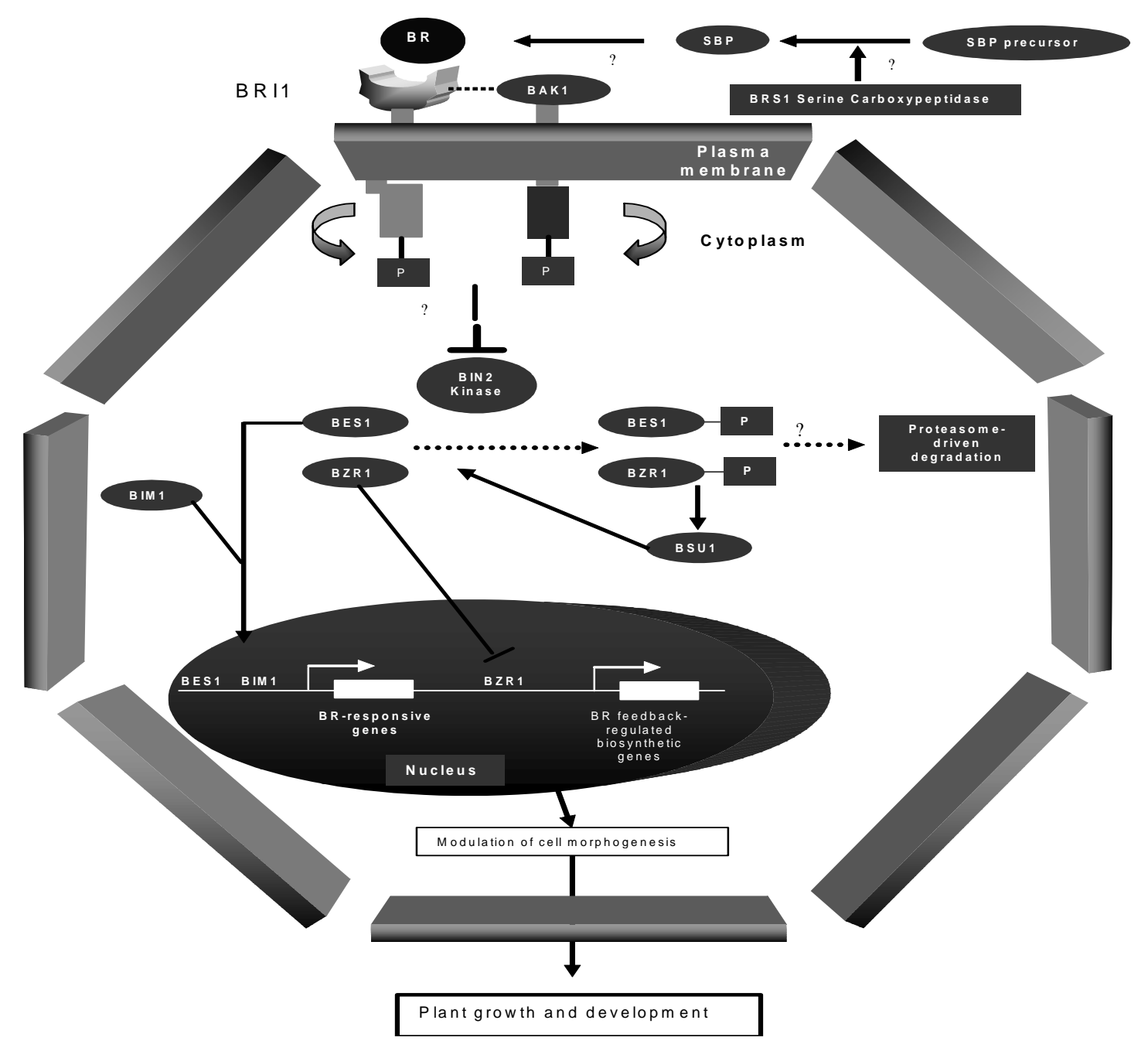

Figure 1 - Working model for the main genes involved in brassinosteroid signal transduction pathway in Arabidopsis.

Brassinosteroids (BRs) are perceived at the plasma membrane by direct binding to the extracellular domain of the BRI1 receptor S/T kinase or before that, it complexes with a still unidentified steroid binding protein (SBP), which may require processing by a serine carboxypeptidase (BRS1). BAK1, which encodes for an LRR-RLK serine/threonine protein kinase, interact in vitro and in vivo with BRI1. BRs are thought to bind to three points in BRI1, its receptor: the $2 \alpha, 3 \alpha$-hydroxyls (Wada et al. 1981), the B ring lactone and the 22 $\alpha, 23 \alpha$-hydroxyls (Kishi et al. 1986). BR perception initiates a signaling cascade through BIN2, and the BSU1 phosphatase, which in turn modulates the phosphorylation state and stability of the nuclear transcription factors BES1 and BZR1, two positive regulators of the BR signaling cascade. Interrogation marks indicate proposed but not demonstrated steps. 
More recently, Sun and Allen (2005) have shown that transgenic Arabidopsis plants expressing cotton bin2 cDNAs show reduced growth and similar phenotypes to the semi-dominant bin2 mutant plants, indicating that the cotton bin 2 genes encode functional bin2 isoforms (Sun and Allen, 2005).

bsu1. The bsul-1d Arabidopsis mutant was identified through a bril supressor screen by activation tagging (Mora-Garcia et al. 2004). bsu1 encodes a plant-specific nuclear phosphatase with a long, Kelch-repeat-containing N-terminal region hooked up to a C-terminal $\mathrm{S} / \mathrm{T}$ phosphatase domain. bsul partially suppresses the dwarf phenotype of the bin2 mutant. Furthermore, in bsul mutants BES1 accumulates in its hypophosphorylated form and in vitro BIN2phosphorylated BES1 is dephosphorylated in the presence of BSU1 protein. Finally, RNAi knockdown plants display a compact phenotype resembling weak bril alleles, which provide further support for a model where BSU1 directly counters the effects of BIN2 on BES1, and likely BZR1 (reviewed in Vert et al., 2005).

$\boldsymbol{d} \boldsymbol{w f 1 2}$. Choe and colleagues (2002) identified two new BR-insensitive mutants (dwarf12-ld and $d w f 12-2 d)$. The semidominant dwf12 mutants displayed the typical morphology of previously reported BR dwarfs but they also exhibited several unique phenotypes such as severe downward curling of the leaves. Similar to bri1 mutants, $d w f 12$ plants accumulated CS and BL, providing further evidence that DWF12 was a component of the BR signaling pathway that included BRI1. Cloning of the $d w f 12$ gene revealed that DWF12 belonged to a member of the glycogen synthase kinase $3 \beta$ family, but differently from the human glycogen synthase kinase $3 \beta$, DWF12 lacked the conserved serine- 9 residue in the auto-inhibitory $\mathrm{N}$ terminus. In addition, $d w f 12-1 d$ and $d w f 12-2 d$ encode changes in consecutive glutamate residues in a highly conserved TREE domain. While comparing their findings with previously published data on two other Arabidopsis mutants, bin2 and ucul, which contain mutations in this TREE domain, Choe and colleagues suggested that the TREE domain was of critical importance for adequate functioning of DWF12/BIN2/UCU1 in the BR signalling cascade. dwarf 9, 10 and 11 mutations have not been reported yet.

bee1, bee2, and bee3. Friedrichsen and coworkers (2002) identified in Arabidopsis three genes, which shared high sequence identity, encoding putative basic helix-loop-helix (bHLH) proteins called BR Enhanced Expression (BEE1, BEE2, and BEE3). These functionally redundant, transcription factors, are induced within 30 minutes of treatment with BL being this induction dependent of functional BRI1 and independent of de novo protein synthesis, making these genes the first early response genes characterized in the BR signal transduction pathway. BEE1, BEE2, and BEE3 were active throughout the plant, and mutants lacking all three proteins were less responsive to BRs (Friedrichsen et al., 2002 and Vert et al., 2005).

bru1. Zurek and Clouse (1994) identified brul in soybean, a gene specifically regulated by BRs during the early stages of elongation. BR application resulted in increased plastic extensibility of the elongating soybean epicotyls walls within $2 \mathrm{~h}$, with a concomitant increase in BRU1 mRNA levels. A direct relationship between the level of BRU1 transcripts and both, magnitude of BR-induced stem elongation and plastic extensibility of the cell wall was also demonstated. BRU1 encodes a protein that shows significant homology to various xyloglucan endotransglycosylases (XETs) (Zurek and Clouse, 1994), enzymes that specifically cleave xyloglucan chains and transfer a fragment of the cleaved chain to an acceptor xyloglucan (Fry, 1995), being the mechanism of BR regulation of BRU1 posttranscriptional. Enzyme assays with the recombinant protein showed that BRU1 was indeed a functional XET. Moreover, a linear relationship has been observed between BR concentrations and extractable XET activities in BR-treated soybean epicotyls (Oh et al., 1998). In addition to that structural changes that reduced or impaired stem elongation in soybean resulted in proportional reduction in brul expression (Clouse, 1997). When seen together, these data strongly suggested an involvement of BRU1 in BRstimulated stem elongation.

tch4. The Arabidopsis $\mathrm{TCH}($ for touch) 4 gene was identified as a XET by sequence similarity and 
enzyme activity (Xu et al., 1995). The recombinant $\mathrm{TCH} 4$ protein has been shown to be capable of catalyzing the transfer of xyloglucan polymer segments to radioactively labeled xyloglucan-derived oligosaccharides to form labeled products (Fry et al., 1992), demonstrating that TCH4 was able to modify a major component of the plant cell wall (Xu et al., 1995). It has also been demonstrated that plants of Arabidopsis exposed to 24-epiBL, a highly active BR (Mandava, 1988), presented higher levels of TCH4 mRNA, compared to untreated plants. In addition to that, $\mathrm{TCH} 4$ expression has been shown to be restricted to expanding tissues and organs that underwent cell wall modification (Xu et al., 1995).

cycd3. Progression through the eukaryotic cell cycle is regulated at the G1/S and G2/M check points by distinct families of cyclin-dependent kinases (CDKs), whose activities are determined by co-ordinated binding of different types of cyclins (Pines, 1995). Among all cyclins, the Dtypes are thought to be critical for the stimulation of cell division (Hu et al., 2000). D-type cyclins $(\mathrm{CycD})$ play key roles in linking the Arabidopsis cell cycle to extracellular and developmental signals, but their regulation at the posttranscriptional level or of their cyclin-dependent kinase (CDK) partners is poorly understood (Healy et al., 2001). In Arabidopsis, overexpression of $c y c d 3$ enable initiation and maintanence of cell division in the absence of cytokinin, which suggests that cytokinins activate cell division through induction of $c y c d 3$ (RiouKhamlichi et al., 1999). Hu and co-workers (2000) identified genes that responded to $\mathrm{BR}$ in $\operatorname{det} 2$ suspension culture, and found that epi-BL upregulated transcription of $c y c d 3$. Epi-BL was also able to substitute cytokinin in culturing of Arabidopsis callus and suspension cells. In addittion to that the epi-BL-driven induction of cycd3 was demonstrated to involve de novo protein synthesis, but no protein phosphorylation or dephosphorylation. cycd3 induction was also found to occur in cells of bri1, a BR-insensitive mutant, which suggested that BR induced $c y c d 3$ transcription through a previously unknown signal pathway in plants. These findings led $\mathrm{Hu}$ and coworkers to conclude that epi-BL stimulated cell division through $c y c d 3$ induction.

bru2. A novel cDNA from BL-treated rice seedlings, tentatively named BR-upregulated gene
2 (bru2), was isolated (Sasuga et al., 2000). The bru 2 could encode an actin effector protein that control polymerization of actin molecules, which provided evidence for the involvement of BRs on the orientation of microtubules in plant cells (Bishop and Yokota, 2001).

exo. The exordium (exo) protein has been identified as a regulator of BR-responsive genes in A. thaliana (Coll-Gracia et al., 2004). The exo gene was characterized as a BR-up-regulated gene. exo overexpression resulted in increased transcript levels of the BR-up-regulated $k c s 1$, exp5, delta tip, and agp4 genes, thought to be involved in the mediation of BR-promoted growth. In addition to that exo overexpressing lines showed enhanced vegetative growth, resembling the features of BRtreated plants.

\section{Conclusions and Future Perspectives}

BRs are perceived at the plasma membrane through direct binding to the BRI1 receptor. BRdriven changes in gene expression are achieved mainly through the modulation of the phosphorylation state of the transcription factors, BES1 and BZR1, involved, respectively, in the promotion of $\mathrm{BR}$ responses and repression of BRfeedback regulated genes. Microarrays analysis has helped to identify a new whole group of BRrelated genes (Goda et al., 2002; Yang et al., 2003), which is predicted to make significantly contribution to the elucidation of the full BR signal transduction pathway.

It is expected, as a practical goal, that detailed insight into the regulation of BRs biosynthesis, signal transduction pathway and action mechanism, will provide new tools for the improvement of crops. For example, ripening control in orchards (Simmons et al., 2006) is expected to be improved, while improved management of shoot architecture in horticulture and forestry has already been achived (Patent BR 000057, Pereira-Netto et al., pending). Furthermore, improved knowledge on BR-related genes might also help to unravel unknown action mechanisms of steroids in animals, especially in mammals. 


\section{ACKNOWLEDGEMENTS}

The author thanks CNPq-Brazil for financial support.

\section{RESUMO}

Genes envolvidos nas vias de biossíntese e de transdução de sinal de brassinoesteróides.

Brassinoesteróides são esteróides vegetais, essenciais para o crescimento e o desenvolvimento, que apresentam um oxigênio no carbono C-3 e oxigênios adicionais em um ou mais dos átomos de carbono C-2, C-6, C-22 e C23. Nos últimos anos, a aplicação de técnicas de genética molecular possibilitou progresso significativo no entendimento da regulação da via biossintética e na identificação de vários componentes da via de transdução de sinal de brassinoesteróides. Buscas em bases de dados eletrônicas mostram dúzias de registros para genes relacionados a brassinoesteróides nos últimos doze meses, demonstrando os grandes esforços desenvolvidos neste campo. Esta revisão destaca os recentes avanços na caracterização de genes e mutações que estão auxiliando na elucidação dos mecanismos moleculares envolvidos na síntese/metabolismo, e percepção e resposta de brassinoesteróides, com ênfase especial no seu papel no alongamento de células vegetais. Aspectos do envolvimento de BRs na regulação de proteínas que controlam o ciclo cellular também são discutidos.

\section{REFERENCES}

Azpiroz, R.; Wu, Y.; LoCascio, J.C. and Feldmann, K.A. 1998. An Arabidopsis brassinosteroiddependent mutant is blocked in cell elongation. Plant Cell, 10, 219-230.

Bajguz, A. and Tretyn, A. (2003), The chemical characteristic and distribution of brassinosteroids in plants. Phytochem., 62, 1027-1046.

Berná , G.; Robles, P. and Micol, J.L. (1999), A mutational analysis $\mathrm{f}$ leaf morphogenesis in Arabidopsis thaliana. Genetics, 152, 729-742.

Bishop, G.J.; Nomura, T.; Yokota, T.; Harrison, K.; Noguchi, T.; Fujioka, S.; Takatsuto, S.; Jones, J.D.G. and Kamiya, Y. 1999. The tomato DWARF enzyme catalyses C-6 oxidation in brassinosteroid biosynthesis. Proc. Nat. Acad. Sci. (U.S.A.), 96, 1761-1766.
Bishop, G.J. and Yokota, T. (2001), Plants steroid hormones, brassinosteroids: Current highlights of molecular aspects on their synthesis/metabolism, transport, perception and response. Plant Cell Physiol., 42, 114-120.

Choe, S.; Dilkes, B.P.; Fujioka, S.; Takatsuto, S.; Sakurai, A. and Feldmann, K.A. (1998), The DWF4 gene of Arabidopsis encodes a cytochrome P450 mediates multiple $22 \alpha$-hydroxylation steps in brassinosteroid biosynthesis. Plant Cell, 10, 231-243.

Choe, S.; Dilkes, B.P.; Gregory, B.D.; Ross, A.S.; Yuan, H.; Noguchi, T.; Fujioka, S.; Takatsuto, S.; Tanaka, A.; Yoshida, S.; Tax, F.E. and Feldmann, K.A. (1999a), The Arabidopsis dwarf1 mutant is defective in the conversion of 24methylenecholesterol to campesterol in brassinosteroid biosynthesis. Plant Physiol., 119, 897907.

Choe, S.; Fujioka, S.; Noguchi, T.; Takatsuto, S.; Yoshida, S. and Feldmann, K.A. (2001), Overexpression of DWARF4 in the brassinosteroid biosynthetic pathway results in increased vegetative growth and seed yield in Arabidopsis. Plant J., 26, 573-582.

Choe, S.; Noguchi, T.; Fujioka, S.; Takatsuto, S.; Tissier, C.P.; Gregory, B.D.; Ross, A.S.; Tanaka, A.; Yoshida, S.; Tax, F.E. and Feldmann, K.A. (1999b), The Arabidopsis dwf7/ste1 mutant is defective in the $\Delta^{7} \quad$ sterol C-5 desaturation step leading to brassinosteroid biosynthesis. Plant Cell, 11, 207-221.

Choe, S.; Schmitz, R.J.; Fujioka, S.; Takatsuto, S.; Lee, M.O.; Yoshida, S.; Feldmann, K.A. and Tax, F.E. (2002), Arabidopsis brassinosteroid-insensitive dwarf12 mutants are semidominant and defective in a glycogen synthase kinase 3beta-like kinase. Plant Physiol., 130, 1506-1515.

Choe, S.; Tanaka, A.; Noguchi, T.; Fujioka, S.; Takatsuto, S.; Ross, A.S.; Tax, F.E.; Yoshida, S. and Feldmann, K.A. (2000), Lesions in the sterol $\Delta^{7}$ reductase gene of Arabidopsis cause dwarfism due to a block in brassinosteroid biosynthesis. Plant J., 21, 431-443.

Chory, J.; Peto, C.; Feinbaum, R.; Pratt, L. and Ausubel, F. (1989), Arabidopsis thaliana mutant that develops as a light-grown plant in the absence of light. Cell, 58, 991-999.

Clouse, S. D. (1997), Molecular genetic analysis of brassinosteroid action. Physiol. Plant., 100, 702-709.

Clouse, S.D. (2002), Brassinosteroid Signal Transduction: Clarifying the pathway from ligand perception to gene expression. Mol. Cell, 10, 973982.

Clouse, S.D.; Langford, M.E. and McMorris, T. C. (1996), A brassinosteroid-insensitive mutant in Arabidopsis thaliana exhibits multiple defects in growth and development. Plant Physiol., 111, 671678. 
Clouse, S.D. and Sasse, J.M. (1998), Brassinosteroids: essential regulators of plant growth and development. Ann. Rev. Plant Physiol. Plant Mol. Biol., 49, 427451.

Coll-Garcia, D; Mazuch, J; Altmann, T. and Mussig, C. (2004), EXORDIUM regulates brassinosteroidresponsive genes. FEBS-Letters, 563, 82-86.

Creelman, R.A. and Mullet, J. E. (1997), Oligosaccharins, brassinolides and jasmonates: nontraditional regulators of plant growth, development and gene expression. Plant Cell, 9, 1211-1223.

Ephritikhine, G.; Pagant, S.; Fujioka, S.; Takatsuto, S.; Lapous, D.; Caboche, M.; Kendrick, R.E. and Barbier-Brygoo, H. (1999), The sax1 mutation defines a new locus involved in the brassinosteroid biosynthesis pathway in Arabidopsis thaliana. Plant J., 18, 315-320

Feldmann, K.A., Marks, M.D., Christianson, M.L., and Quatrano, R.S. (1989). A dwarf mutant of Arabidopsis generated by T-DNA insertion mutagenesis. Science, 243, 1351-1354.

Friedrichsen, D.M.; Joazeiro, C.A.P.; Li, J., Hunter, T. and Chory, J. (2000), Brassinosteroid-insensitive-1 is a ubiquitously expressed leucine-rich repeat receptor serine/threonine kinase. Plant Physiol., 123, 12471256.

Friedrichsen, D. M.; Nemhauser, J.; Muramitsu, T.; Maloof, J.N.; Alonso, J.; Ecker, J.R.; Furuya, M. and Chory, J. (2002), Three redundant brassinosteroid early response genes encode putative bHLH transcription factors required for normal growth. Genetics, 162, 1445-1456.

Fry, S.C. (1995), Polysaccharide-modifying enzymes in the plant cell wall. Ann. Rev. Plant Physiol. Plant Mol. Biol., 46, 497-520.

Fry, S.C.; Smith, R.C.; Renwick, K.F.; Martin, D.J.; Hodge, S.K. and Matthews, K.J. (1992), Xyloglucan endotransglycosylase, a new wall-loosening enzyme activity from plants. Biochem. J., 282, 821-828.

Fujioka, S.; Li, J.; Choi, Y.-H.; Seto, H.; Takatsuto, S.; Noguchi, T.; Watanabe, T.; Kuriyama, H.; Yokota, T.; Chory, J. and Sakurai, A. (1997), The Arabidopsis deetiolated2 mutant is blocked early in brassinosteroid biosynthesis. Plant Cell, 9, 19511962.

Goda, H.; Shimada, Y.; Asami, T.; Fujioka, S. and Yoshida, S. (2002), Microarray analysis of brassinosteroid-regulated genes in Arabidopsis. Plant Physiol., 130, 1319-1334.

He, J. X.; Gendron, J. M.; Sun, Y.; Gampala, S.S.L.; Gendron, N.; Sun, C.Q. and Wang, Z.Y. (2005), BZR1 is a transcriptional repressor with dual roles in brassinosteroid homeostasis and growth responses. Science, 307, 1634-1638.
Healy, J.M.S.; Menges, M.; Doonan, J.H. and Murray, J.A.H. (2001), The Arabidopsis D-type cyclins $\mathrm{CycD} 2$ and $\mathrm{CycD} 3$ both interact in vivo with the PSTAIRE cyclin-dependent Kinase $\mathrm{Cdc} 2 \mathrm{a}$ but are differentially controlled. J. Biol. Chem., 276, 70417047.

Hu, Y.; Bao, F. and Li, J. (2000), Promotive effect of brassinosteroids on cell division involves a distinct CycD3-induction pathway in Arabidopsis. Plant J., 24, 693-701.

Kauschmann, A.; Jessop, A.; Koncz, C.; Szekeres, M.; Willmitzer, L. and Altmann, T. (1996), Genetic evidence for an essential role of brassinosteroids in plant development. Plant J., 9, 701-713.

Kim, G.Y.; Fujioka, S.; Kozuka, T.; Tax, F.E.; Takatsuto, S.; Yoshida, S. and Tsukaya, H. (2005), CYP90C1 and CYP90D1 are involved in different steps in the brassinosteroid biosynthesis pathway in Arabidopsis thaliana. Plant J., 41, 710-721.

Kinoshita, T.; Cano-Delgado, A.; Seto, H.; Hiranuma, S.; Fujioka, S.; Yoshida, S. and Chory J. 2005. Binding of brassinosteroids to the extracellular domain of plant receptor kinase BRI1. Nature, 433, 167-71.

Klahre, U.; Noguchi, T.; Fujioka, S.; Takatsuto, S.; Yokota, T.; Nomura, T.; Yoshida, S. and Chua, N.H. (1998), The Arabidopsis DIMINUTO/DWARF1 gene encodes a protein involved in steroid synthesis. Plant Cell, 10, 1677-1690.

Koka, C.V.; Cerny, R.E.; Gardner, R.G.; Noguchi, T.; Fujioka, S.; Takatsuto, S.; Yoshida, S. and Clouse, S. D. (2000), A putative role for the tomato genes DUMPY and CURL-3 in brassinosteroid biosynthesis and response. Plant Physiol., 122, 85-98.

Laxmi, A.; Paul, L.K.; Peters, J.L. and Khurana, J.P. (2004), Arabidopsis constitutive photomorphogenic mutant, bls1, displays altered brassinosteroid response and sugar sensitivity. Plant Mol. Biol., 56, 185-201.

Li, J.; Biswas, M.G.; Chao, A.W.; Russell, D. and Chory, J. (1997), Conservation of function between mammalian and plant steroid $5 \alpha$-reductases. Proc. Nat. Acad. Sci. (U.S.A.), 94, 3554-3559.

Li, J. and Chory, J. (1997), A putative leucine-rich repeat receptor kinase involved in brassinosteroid signal transdution. Cell, 90, 929-938.

Li, J. and Chory, J. (1999b), Brassinosteroid actions in plants. J. Exp. Bot., 50, 275-282.

Li, L. and Deng, X.W. (2005), It runs in the family: regulation of brassinosteroid signaling by the BZR1BES1 class of transcription factors. Trends Plant Sci., 10, 266-268.

Li, J.; Lease, K.A.; Tax, F.E. and Walker, J.C. (2001a), $B R S 1$, a serine carboxypeptidase, regulates BRI1 signaling in Arabidopsis thaliana. Proc. Nat. Acad. Sci. (U.S.A.), 98, 5916-5921. 
Li, J.; Nagpal, P.; Vitart, V.; McMorris, T. C. and Chory, J. (1996), A role for brassinosteroids in lightdependent development of Arabidopsis. Science, 272, 398-401.

Li, J. and Nam, K. H. (2002), Regulation of brassinosteroid signaling by a GSK3/SHAGGY-like kinase. Science, 295, 1299-1301.

Li, J.; Nam, K.H.; Vafeados, D. and Chory, J. (2001b), BIN2, a New Brassinosteroid-Insensitive Locus in Arabidopsis. Plant Physiol., 127, 14-22.

Li, J.; Wen, J.; Lease, K.A.; Doke, J.T.; Tax, F.E. and Walker JC. BAK1, an Arabidopsis LRR receptor-like protein kinase, interacts with BRI1 and modulates brassinosteroid signaling. Cell, 110, 213-22.

Mandava, N.B. (1988), Plant growth-promoting brassinosteroids. Ann. Rev. Plant Physiol. Plant Mol. Biol., 39, 23-52.

Montoya,T.; Nomura, T.; Farrar, K.; Kaneta, T.; Yokota, T. and Bishop, G.J. 2002. Cloning the tomato curl3 gene highlights the putative dual role of the leucine-rich repeat receptor kinase tBRI1/SR160 in plant steroid hormone and peptide hormone signaling. Plant Cell, 14, 3163-3176.

Mora-Garcia, S.; Vert, G.; Yin, Y.; Cano-Delgado, A.; Cheong, H. and Chory J. 2004. Nuclear protein phosphatases with Kelch-repeat domains modulate the response to brassinosteroids in Arabidopsis. Genes Dev., 18, 448-460.

Mori, M.; Nomura, T.; Ooka, H.; Ishizaka, M.; Yokota, T.; Sugimoto, K.; Okabe, K.; Kajiwara, H.; Satoh, K.; Yamamoto, K.; Hirochika, H. and Kikuchi, S. (2002), Isolation and characterization of a rice dwarf mutant with a defect in brassinosteroid biosynthesis. Plant Physiol., 130, 1152-1161.

Nam, K.H. and Li, J.M. (2004), The Arabidopsis transthyretin-like protein is a potential substrate of Brassinosteroid-Insensitive 1. Plant Cell, 16, 24062417.

Neff, M.M.; Nguyen, S.M.; Malancharuvil, E.J.; Fujioka, S.; Noguchi, T.; Seto, H.; Tsubuki, M.; Honda, T.; Takatsuto, S.; Yoshida, S. and Chory, J. (1999), BAS1: A gene regulating brassinosteroid levels and light responsiveness in Arabidopsis. Proc. Nat. Acad. Sci. (U.S.A.), 96, 15316-15323.

Noguchi, T.; Fujioka, S.; Takatsuto, S.; Sakurai, A.; Yoshida, S.; Li, J. and Chory, J. (1999), Arabidopsis det 2 is defective in the conversion of (24R)-24methylcholest-4-en-3-one to (24R)-24-methyl-5cholestan-3-one in brassinosteroid biosynthesis. Plant Physiol., 120, 833-839.

Nomura, T; Bishop, G.J.; Kaneta, T.; Reid, J.B.; Chory, J. and Yokota, T. (2003), The LKA gene is a BRASSINOSTEROID INSENSITIVE 1 homolog of pea. Plant Physiol., 36, 291-300.
Nomura, T.; Jager, C.E.; Kitasaka, Y.; Takeuchi, K.; Fukami, M.; Yoneyama, K.; Matsushita, Y.; Nyunoya, H.; Takatsuto, S.; Fujioka, S.; Smith, J.J.; Kerckhoffs, L.H.J.; Reid, J.B. and Yokota, T. (2004), Brassinosteroid deficiency due to truncated steroid 5 alpha -reductase causes dwarfism in the $1 \mathrm{k}$ mutant of pea. Plant Physiol., 135, 2220-2229.

Nomura, T.; Kitasaka, Y.; Takatsuto, S.; Reid, J.B.; Fukami, M. and Yokota, T. (1999), Brassinosteroid/sterol synthesis and plant growth as affected by $l k a$ and $l k b$ mutations of pea. Plant Physiol., 119, 1517-1526.

Nomura, T.; Kushiro, T.; Yokota, T.; Kamiya, Y.; Bishop, G.J. and Yamaguchi, S. (2005), The last reaction producing brassinolide is catalyzed by cytochrome P-450s, CYP85A3 in tomato and CYP85A2 in Arabidopsis. J. Biol. Chem., 280, 17873-17879.

Nomura, T.; Nakayama, M.; Reid, J.B.; Takeuchi, Y. and Yokota, T. (1997), Blockage of brassinosteroid synthesis and sensitivity causes dwarfism in Pisum sativum. Plant Physiol., 113, 31-37.

Oh, M.H.; Ray, W.K.; Huber, S.C.; Asara, J.M.; Gage, D.A. and Clouse, S.D. (2000), Recombinant brassinosteroid insensitive 1 receptor-like kinase autophosphorylates on serine and threonine residues and phosphorylates a conserved peptide motif in vitro. Plant Physiol., 124, 751-765.

Oh, M.H.; Romanow, W.; Smith, R.; Zamski, E.; Sasse, J. and Clouse, S. (1998), Soybean BRU1 encodes a functional xyloglucan endo-transglycosylase that is highly expressed in inner epicotyl tissues during brassinosteroid-promoted elongation. Plant Cell Physiol., 39, 124-130.

Pérez-Pérez, J.M.; Ponce, M.R. and Micol, J.L. (2002), The UCU1 Arabidopsis Gene Encodes a SHAGGY/GSK3-like Kinase Required for Cell Expansion along the Proximodistal Axis. Develop. Biol., 242, 161-173.

Pines, J. (1995), Cyclins and cyclin-dependent kinases: a biochemical view. Biochem. J., 308, 697-711

Riou-Khamlichi, C.; Huntley, R.; Jacqmard, A. and Murray, J.A.H. (1999), Cytokinin activation of Arabidopsis cell division through a D-type cyclin. Science, 283, 1541-1544.

Russinova, E.; Borst, J.W.; Kwaaitaal, M.; CanoDelgado, A.; Yin, Y.H.; Chory, J. and Vries, S.C. de. (2004), Heterodimerization and endocytosis of Arabidopsis brassinosteroid receptors BRI1 and AtSERK3 (BAK1). Plant Cell, 16, 3216-3229.

Sasuga, Y.; Tanaka, S. and Tekenaga, H. (2000), Possible mechanism of the cell elongation induced by brassinolide in rice seedlings. Plant Cell Physiol., 41 (supplement), s200.

Sun, Y. and Allen, R.D. 2005. Functional analysis of the bin2 genes of cotton. Mol. Genet. Genom. 274, 51-59 
Symons, G.M.; Davies, C.; Shavrukov, Y.; Dry, I.B.; Reid, J.B. and Thomas, M.R. 2006. Grapes on steroids. Brassinosteroids are involved in grape berry ripening. Plant Physiol., 140, 150-158.

Szekeres, M.; Nemeth, K.; Koncz-Kalman, Z.; Mathur, J.; Kauschmann, A.; Altmann, T.; Redei, G.P.; Nagy, F.; Schell, J. and Koncz, C. (1996), Brassinosteroids rescue the deficiency of CYP90, a cytochrome P450, controlling cell elongation and de-etiolation in Arabidopsis. Cell, 85, 171-182.

Takahashi, N.; Nakazawa, M.; Shibata, K.; Yokota, T.; Ishikawa, A.; Suzuki, K.; Kawashima, M.; Ichikawa, T.; Takahashi, T.; Gasch, A.; Nishizawa, N. and Chua, N.H. (1995), The DIMINUTO gene of Arabidopsis is involved in regulating cell elongation. Genes Develop., 9, 97-107.

Takahashi, N.; Nakazawa, M.; Shibata, K.; Yokota, T.; Ishikawa, A.; Suzuki, K.; Kawashima, M.; Ichikawa, T.; Shimada, H. and Matsui M (2005), shk1-D, a dwarf Arabidopsis mutant caused by activation of the CYP72C1 gene, has altered brassinosteroid levels. Plant J., 42, 13-22.

Tanabe, S.; Ashikari, M.; Fujioka, S.; Takatsuto, S.; Yoshida, S.; Yano, M.; Yoshimura, A.; Kitano, H.; Matsuoka, M.; Fujisawa, Y.; Kato, H. and Iwasaki, Y. (2005), A novel cytochrome P450 is implicated in brassinosteroid biosynthesis via the characterization of a rice dwarf mutant, dwarf11, with reduced seed length. Plant Cell, 17, 776-790.

Tanaka, K.; Asami, T.; Yoshida, S.; Nakamura, Y.; Matsuo, T. and Okamoto, S. 2005. Brassinosteroid homeostasis in Arabidopsis is ensured by feedback expressions of multiple genes involved in its metabolism. Plant Physiol., 138, 1117-1125.

Turk, E.M.; Fujioka, S.; Seto, H.; Shimada, Y.; Takatsuto, S.; Yoshida, S.; Wang, H.C.; Torres, Q.I.; Ward, J.M.; Murthy, G.; Zhang, J.Y.; Walker, J.C. and Neff, M.M. (2005), BAS1 and SOB7 act redundantly to modulate Arabidopsis photomorphogenesis via unique brassinosteroid inactivation mechanisms. Plant J., 42, 23-34.
Vert, G.; Nemhauser, J.L.; Geldner, N.; Hong, F. and Chory, J. 2005. Molecular mechanisms of steroid hormone signaling in plants. Ann. Rev. Cell Dev. Biol., 21, 177-201.

Wang, Z.Y.; Nakano, T.; Gendron, J.; He, J. X.; Chen, M.; Vafeados, D.; Yang, Y.L.; Fujioka, S.; Yoshida, S.; Asami, T. and Chory, J. (2002), Nuclear-localized BZR1 mediates brassinosteroid-induced growth and feedback suppression of brassinosteroid biosynthesis. Develop. Cell, 2, 505-513.

Wang, Z.Y.; Seto, H.; Fujioka, S.; Yoshida, S. and Chory, J. (2001), BRI1 is a critical component of a plasma-membrane receptor for plant steroids. Nature 410, 380-383.

$\mathrm{Xu}$, W.; Prugganan, M. M.; Polisensky, D.H.; Antosiewicz, D.M.; Fry, S.C. and Braam, J. (1995), Arabidopsis $\mathrm{TCH} 4$, regulated by hormones and the environment, encodes a xyloglucan endotransglycosylase. Plant Cell, 7, 1555-1567.

Yang, G.X.; Matsuoka, M.; Iwasaki, Y. and Komatsu, S. (2003), A novel brassinolide-enhanced gene identified by cDNA microarray is involved in the growth of rice. Plant Mol. Biol., 52, 843-854.

Yin, Y.; Wang, Z.Y.; Mora-Garcia, S.; Li, J.; Yoshida, S.; Asami, T. and Chory, J. (2002), BES1 accumulates in the nucleus in response to brassinosteroids to regulate gene expression and promote stem elongation. Cell, 109, 181-191

Yin Y, Vafeados D, Tao Y, Yoshida S, Asami T, Chory J. 2005. A new class of transcription factors mediates brassinosteroid-regulated gene expression in Arabidopsis. Cell, 120, 249-59

Zhou, A.F. and Li, J. 2005. Arabidopsis BRS1 is a secreted and active serine carboxypeptidase. J. Biol. Chem., 280, 35554-35561

Zurek, D.M. and Clouse, S.D. (1994), Molecular cloning and characterization of a brassinosteroidregulated gene from elongating soybean (Glycine max L.) epicotyls. Plant Physiol., 104, 161-170. 